\title{
White spots on Smoke Rings by Bruce Nauman: Microanalytical study of a contemporary artwork
}

Cardeira, A.M. .,**, Câmara, R.B. ${ }^{* *}$, Strzelec, P. ${ }^{* * *}$, Longelin, S. ${ }^{* *}$, Schiavon, N. ${ }^{* * * *}$, Candeias, A. ${ }^{* * * * * * * * *}$, Carvalho, M.L. ${ }^{* * * * * * * * *}$, Manso, M. ${ }^{*, * *}$

* Faculdade de Belas-Artes da Universidade de Lisboa, Largo da Academia Nacional de Belas-Artes, 1249058 Lisboa, PORTUGAL.

** Centro de Física Atómica da Universidade de Lisboa, Av. Professor Gama Pinto 2, 1649-003 Lisboa, PORTUGAL.

**** Mason Gross School of the Arts of the University of Rutgers, 330 Livingston Ave, New Jersey, UNITED STATES OF AMERICA.

**** Laboratório HERCULES, Universidade de Évora, Largo Marquês de Marialva 8, 7000 Évora, PORTUGAL.

****** Laboratório José de Figueiredo, Direcção Geral do Património Cultural, Rua das Janelas Verdes 37, 1249-018 Lisboa, PORTUGAL.

******* Departamento de Física, Faculdade de ciências e Tecnologia, Universidade Nova de Lisboa, Caparica, PORTUGAL.

Email: marta974@cii.fc.ul.pt

The artwork Smoke Rings: Two Concentric Tunnels, Non-Communicating (1980) by Bruce Nauman represents a case-study of conservation of a contemporary artwork. Smoke Rings $(462 \times 53.3 \times 0 \mathrm{~cm})$ was made starting with a plaster model which was then casted to Aluminum alloy; a black patina was then applied by The Sculpture Foundation's Johnson Atelier Division, New Jersey, USA. The artwork is currently exhibited at the Museum Collection Berardo, Lisbon, Portugal.

The main concern over this artwork is related to the widespread presence of white spots on its surface, due to degradation over time. In fact, despite it displaying today a greyish color dotted with white spots, documents from the atelier reports the artwork to be originally black.

The main objective of this work was the detailed chemical characterization of the alloy substrate, the patina and the white spots in order to understand possible causes for the observed decay degradation patterns. In order to achieve this objective, a multianalytical approach was adopted involving first in situ non destructive analyses at the museum by Digital Microscopy (AM4013-FVW Dino-Lite Pro) and Energy Dispersive X-ray Fluorescence (Eclipse IV Oxford Instruments Rh X-ray generator and Amptek XR-100SDD detector) to identify the best areas for micro-sampling and provide preliminary elemental characterization of alloy, patina and white spots (Fig. 1). Micro-samples were analyzed by means of Scanning Electron Microscopy with Energy Dispersive Spectroscopy (HITACHI® S3700N and Bruker AXS X-Flash®). Concerning the alloy substrate, a very pure Al alloy from the 6000 series Al-Si-Mg (Fig. 2) was identified [1]. Patina composition results were in agreement with the documentation provided by the atelier [2-3]. White spots may be characterized by the presence of Zirconium $(\mathrm{Zr})$ since this element is neither related with the Aluminium alloy or patina. Size, morphology and elemental composition of the $\mathrm{Zr}$ particles, show that it's most likely to be a Zirconium silicate rather than a Zirconium oxide (Fig. 2).

From a conservator point of view, many causes can be the source of the presence of this element, such as elimination of an original protective layer applied by the atelier, polluted waters used to prepare the patina or even exposure to polluted outdoors air causing this kind of degradation. 
Future work may involve an investigation of outdoor air where the artwork was exposed and experiments over the artwork surface taking into account the preserved Aluminium alloy underneath.

The authors would like to acknowledge the Museum Collection Berardo for lending this artwork understudy.

[1] Baïlon J. P. and Dorlot J. M., Des Matériaux. Presses inter Polytechnique, Paris, 2000.

[2] Material Safety Data Sheet - ALUMA BLACK® A14 Brush-On Blackener. Available at http://www.emedco.info/rtk/common/wcd00007/wcd007ee.htm.

[3] Material Safety Data Sheet - ALUMA BLACK® A15 Immersion. Available at http://www.drs.illinois.edu/msds/DownloadFile.aspx?Guid=115EA966-334D-4496-8A92-4071411DD7F8.
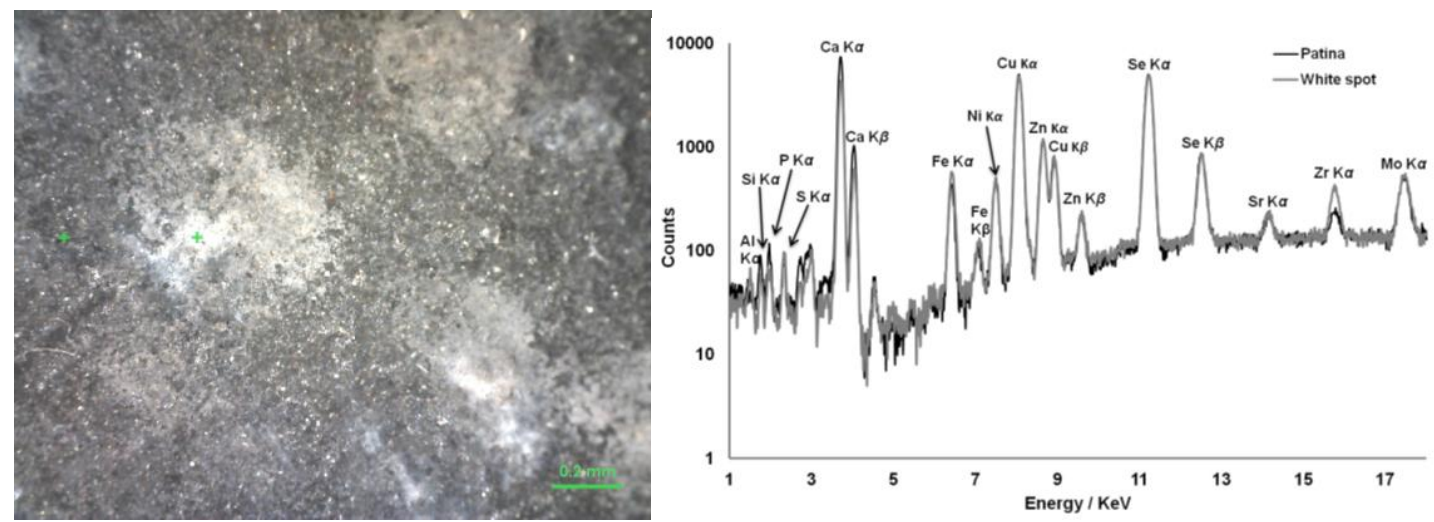

Figure 1. Digital Microscopy image of white spot and respectively EDXRF spectra of patina and white spot.
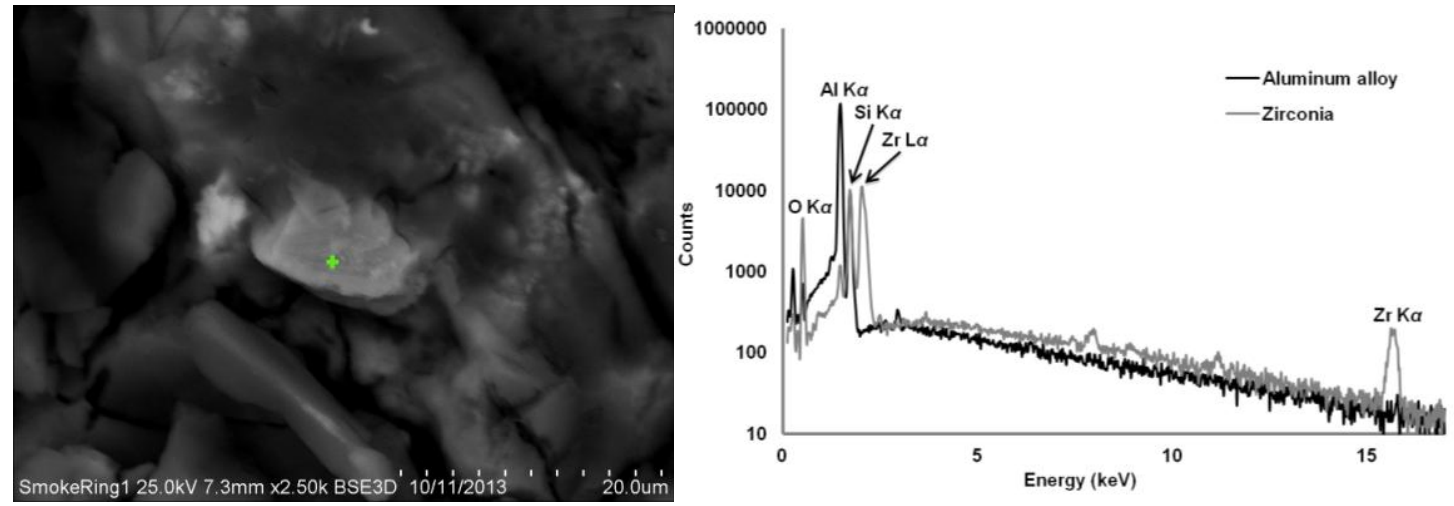

Figure 2. SEM image of Zirconium particle on patina's surface and respectively XRF spectra of Zirconia grain. 